\title{
Influence of Different Factors on Abundance Estimates Obtained from Simultaneous Sonar and Echo Sounder Recordings
}

\author{
Eli Kyrkjebø Haugland and Ole Arve Misund*
}

Institute of Marine Research, P.O. Box 1870, N-5817 Bergen, Norway

\begin{abstract}
Use of horizontal guided sonar in addition to vertical echo sounder may improve biomass estimation of pelagic fish schooling near the surface. But proportions of horizontal guided sonar to vertical echo integration estimates have been shown to be very variable, and it is necessary to provide better knowledge on factors that influence acoustic recordings of fish near surface before a reliable method of combining sonar and echo integration estimates can be established. To explore factors that influence horizontal sonar recordings of fish biomass near surface, we collected and analysed data from two acoustic surveys on Norwegian spring-spawning herring (Clupea harengus L.) in the Norwegian Sea in 1997 and 1998, and two acoustic surveys off the southwest coast of Africa, investigating pilchard (Sardinops sagax), anchovy (Engraulis capensis) and round herring (Etrumeus whiteheadi) off the coast of Namibia in 1994, and sardinella (Sardinella sp.) off the coast of Angola in 1995. The ratios of fish densities obtained by sonar to those obtained by echo sounder varied both with respect to location and between different years within a specific location. For three of the four surveys, the biomass estimated by sonar was significantly higher than the estimates by echo sounder, whereas in the remaining survey there was no significant difference in estimated biomass. Periods of bad weather, shallow, or lowdensity patchy fish distributions and mixture of the target species with other species contributed to the higher and more variable sonar estimates. Still a goal should be to improve knowledge about the factors that contributes to variations between simultaneously recorded echo sounder and sonar data. An aim should be to combine the recordings from both methods in the biomass estimations, or at least assess which of the estimates that are less biased under the prevailing environmental conditions and actual school distribution.
\end{abstract}

Keywords: Sonar, echo sounder, acoustics, abundance estimation, biomass, pelagic schooling fish.

\section{INTRODUCTION}

Fish distributed close to the surface, not available to the acoustic beam of a vertically observing hull-mounted echo sounder, can be recorded by sonar [1, 2]. However, handling of the collected sonar data introduce new challenges compared to the traditional and well-documented use of the echo sounder. It is important to be aware of the limitations and advantages to utilize the potential of the sonar in sampling and studies of pelagic fish.

When subject to acoustic observations, fish will often alter their normal behaviour due to stimuli from the survey vessel. This leads to bias in the acoustic observations [3]. This bias is partly unknown and variable [4], and conesquently a simple data correction is generally not possible. A combined method, including both sonar and echo sounder, has been suggested to improve biomass estimation of fish schooling close to the surface $[2,5]$ and for the study of fish behaviour in the presence of a vessel [6-8]. There are two main methods applied in the conversion from sonar recordings to fish biomass. The first method requires knowledge of the backscattered echo intensity $[9,10]$. The second method makes use of the relationship between school area/volume

*Address correspondence to this author at the Institute of Marine Research, Department of Marine Resources, P.O. Box 1870, N-5817 Bergen, Norway; Institute of Marine Research, Department of Marine Environment, P.O. Box 1870, N-5817 Bergen, Norway; Tel: +4755238497; Fax: +4755238584; E-mail: olem@imr.no and school biomass. Such relationships have been established for pelagic fish species in both a geometric and a logarithmic domain [11-13].

This paper presents fish density estimates based on geometric conversions of sonar recordings from the Norwegian Sea and off the southwest coast of Africa. The sonar density estimates will be compared with density estimates from standard echo integration of echo sounder data. It was also an aim to compare the two recording methods for different pelagic clupeid schooling species living in these different ecosystems. In order to address the stability between sonar and echo sounder estimates in time, data from the 1997 and 1998 surveys of Norwegian spring-spawning herring (Clupea harengus L.) in the Norwegian Sea was investigated.

\section{METHODOLOGY}

\section{The Surveys}

Data were collected during surveys with two Norwegian fishery research vessels, «R/V G.O. Sars» and «R/V Dr. Fridtjof Nansen». Both vessels are equipped with sonars and echo sounders that permit simultaneous recordings. Data were collected from two acoustic surveys investigating Norwegian spring-spawning herring in the Norwegian Sea in May 1997 (N.S.97) and in May 1998 (N.S.98), and two acoustic surveys off the southwest coast of Africa, investigating pilchard (Sardinops sagax), anchovy (Engraulis capensis) and round herring (Etrumeus whiteheadi) off the 
coast of Namibia in November/December 1994 (Nam.94) and sardinella (Sardinella sp.) off the coast of Angola in March 1995 (Ang.95). An elementary sampling distance unit (ESDU) of 5 nautical miles ( 1 nautical miles $=1 \mathrm{nmi}=1852$ $\mathrm{m})$ was used to compare the biomass estimates between the surveys. The number of usable ESDUs of the surveys varied from 235 in Ang.95 to 521 in Nam.94.

\section{The Sonar Recording}

The sonar recordings were made using a $95 \mathrm{kHz}$ highresolution SIMRAD SA950 narrow-beam sector scanning sonar. The sonar beam is transmitted in a $45^{\circ}$ horizontal and $10^{\circ}$ vertical sector, relative to $3 \mathrm{~dB}$ opening angles. The echo is received by 32 single beams with $1.7^{\circ}$ horizontally opening angle and $10^{\circ}$ vertically opening angle. The depth of the transducer will be approximately $6 \mathrm{~m}$, it is trainable \pm $200^{\circ}$, tiltable $+10^{\circ}$ to $-90^{\circ}$ and mechanically stabilized for roll and pitch. During the surveys, the sonar was operated at full transmission power, with time varied gain (TVG), a frequency-modulated pulse (FM-AUTO), a gain step of 7, and with the ping filters set to «Weak». The tilt angle was set to $-5^{\circ}$ and the train of the sonar was normally $90^{\circ}$ to starboard or port side. To enable computer-based measurements and detection of schools, a software system was connected to the sonar [12, 14], it exist a newer software system [15] for data collected by the sonar SF950. The computer based school detection system was set to a detection threshold of 10 (Nam.94, Ang.95) or varied between 10 and 15 (N.S.97, N.S.98), excluding weak targets. Continuous colour printouts of the sonar recordings were done during all surveys, the colours from blue to red indicate increasing density of the targets. The density of a target, $\mathrm{C}_{\text {sum }}$ (Colour sum) was given by the integrated reflected echo intensity from the "echo envelope's that build up a school [16]. Each "echo envelope" received a colour code that is the scaled value from the formula:

Colour code $=(64 \cdot \log ($ echo envelope $) /(327.8))+6.4 \cdot$ display gain

Because $\mathrm{C}_{\text {sum }}$ is given in a relative scale that indicate different school densities, the $\mathrm{C}_{\text {sum }}$ does not have any units.

\section{Analysis of the Sonar Data}

The data recorded by the sonar were post-processed in applications in SAS [17]. The standard recording range for the sonar was set from $50 \mathrm{~m}$ (to prevent near field effects) to $300 \mathrm{~m}$ (to secure detectability) to the side of the vessel. To be included in the analyses, the school had to be detected in at least four pings and the diameter should exceed $5 \mathrm{~m}$. Detections of unwanted echoes from bottom, surface air plumes, propeller wakes, false echoes during CTD-sampling and trawling were manually removed. For each separate school, the maximum horizontal school area was stored for further analysis. The recording frequency of the schools and the mean school area with increasing range $(50$ to $300 \mathrm{~m})$ were plotted for each survey. The distribution of the area and $\mathrm{C}_{\text {sum }}$ of the schools were tested against increasing range with regression analysis.

For the Norwegian spring-spawning herring, the sonar recordings were converted to fish density by the relationship: fish density $(\mathrm{kg})=18.4 \cdot$ school area $\left(\mathrm{m}^{2}\right)[12,18]$. For
African species, the applied relationship was: fish density $(\mathrm{kg})=10.4 \cdot$ school area $\left(\mathrm{m}^{2}\right)$ [5]. The variation of converting area to biomass has been found to be of a factor of 10 $[11,12]$, and the method must be seen as a step in the continuous development of more precise abundance estimation methods. The biomass estimates of the recording range were expanded out to the standard integration range of 1 nautical mile. The mean density estimates for the ESDU were calculated. If not all of the five nautical miles in an ESDU had valid recordings, the biomass estimates were based on the usable miles and scaled up to the standard ESDU.

Especially in the N.S.97 survey and partly in Nam.94, some locations showed a more or less patchy, low-density continuous fish/plankton layer (Fig. 1). As the software connected to the sonar system has been shown not to handle such distributions [5], when prevalent such layers were sorted out either by reducing the sampling range of the sonar for the actual nautical miles or by excluding the miles altogether. In N.S.98, track lines with clearly defined schools (Fig. 2) were more widespread than for N.S.97. Heavy rolling and pitching of the vessel caused the sonar beam to tip up and down with the result that a given school switched in and out of the sonar detection sector several times when the vessel passed the school. A single school could then be separated into several fragments, with each fragment to be miss-sampled as a separate school by the detection program (Fig. 3). The automatic detections by the sonar were compared with manual counting of the schools for 25 nautical miles in N.S.97 and N.S.98, to study the effect of miss sampling of school fragment as a consequence of heavy rolling of the vessel.

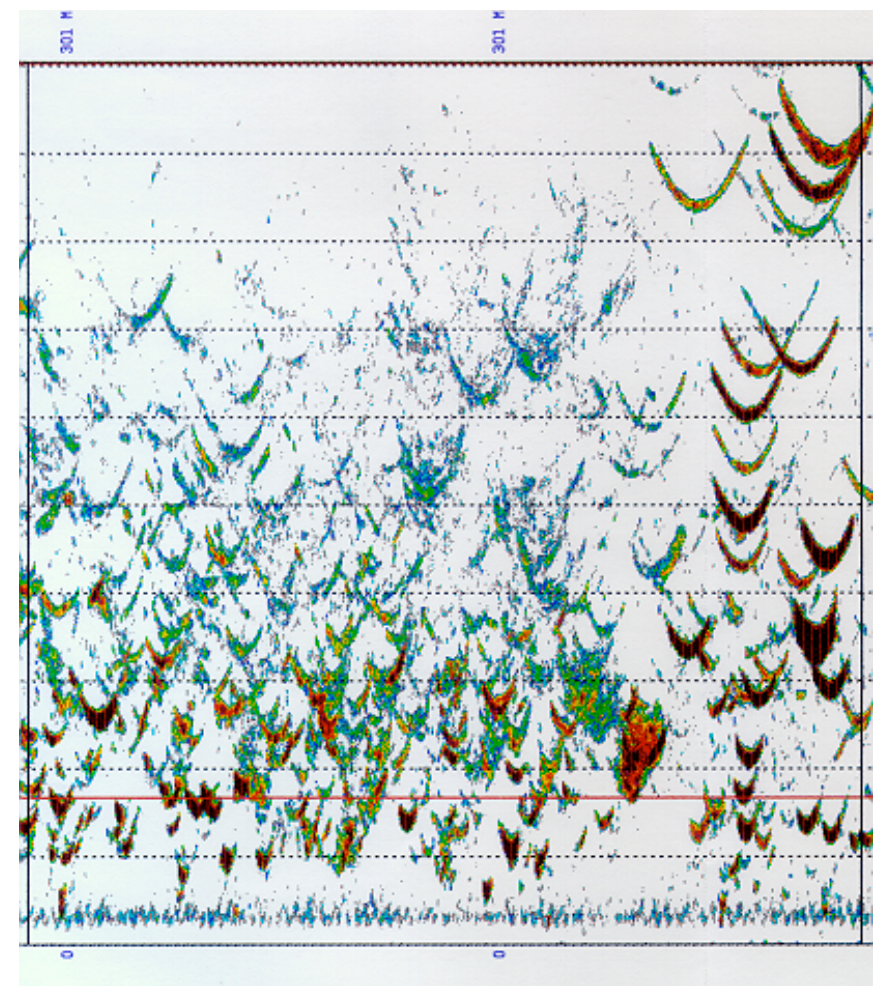

Fig. (1). Sonar recordings from the Norwegian Sea in 1997 showing low density scattered aggregations. The scale is $1 \mathrm{nmi}$ on the horizontal axis and $300 \mathrm{~m}$ on the vertical axis. 


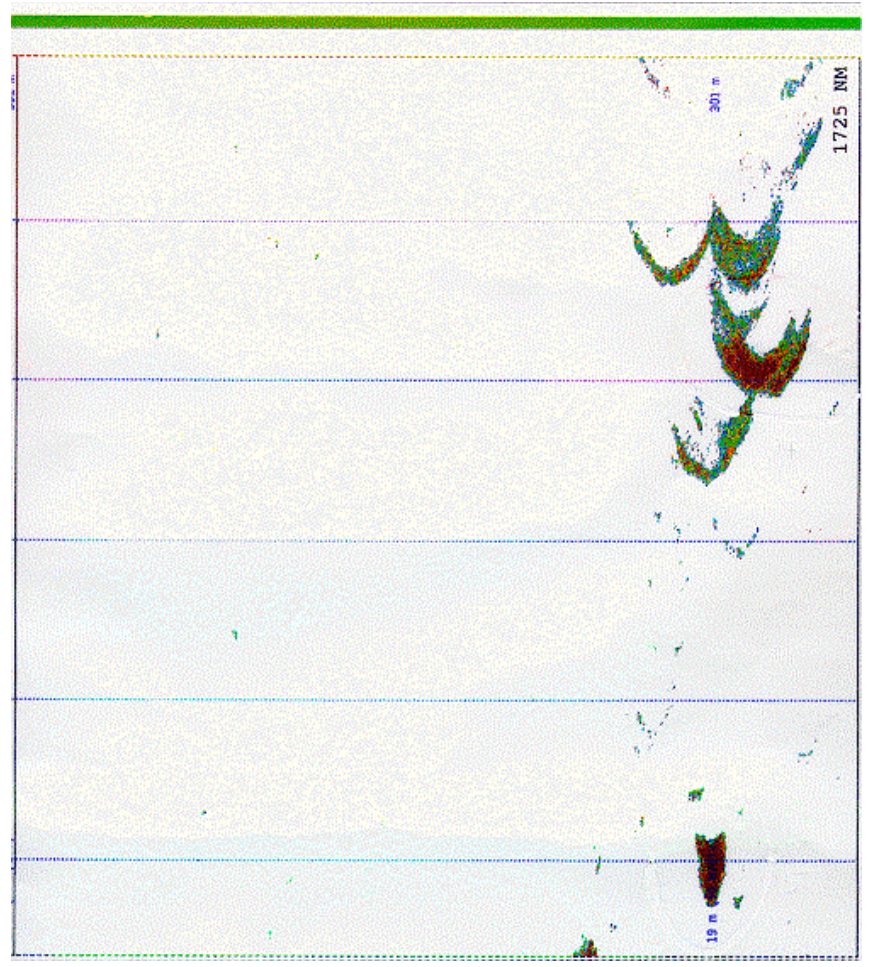

Fig. (2). Sonar recordings from the Norwegian Sea in 1998 showing sonar registrations of suitable fish distribution and in good weather condition. The scale is $1 \mathrm{nmi}$ on the horizontal axis and 300 $\mathrm{m}$ on the vertical axis.

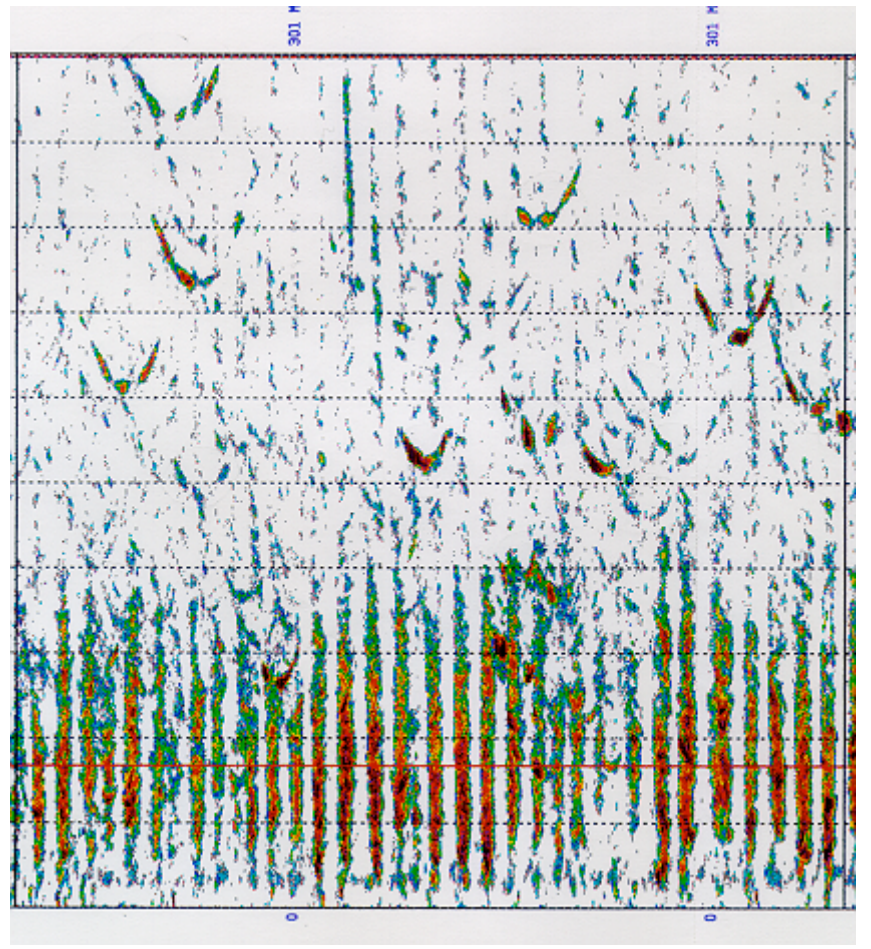

Fig. (3). Sonar recordings from the Norwegian Sea in 1997 during bad weather condition. The scale is $1 \mathrm{nmi}$ on the horizontal axis and $300 \mathrm{~m}$ on the vertical axis.

\section{The Echo Sounder Recording}

Echo-integration during the surveys was carried out using the Bergen Echo Integrator-system (BEI) [19] connected to a
$38 \mathrm{kHz}$ SIMRAD EK500 echo sounder. The beam-width of the SIMRAD ES38B transducer was $6.9^{\circ}$ and the transmit power was $2 \mathrm{~kW}$, the time varied gain function (TVG) was $20 \log \mathrm{R}$, and the pulse duration was $0.6 / 1 \mathrm{~ms}^{-1}$. The vertical integration channels were $50 \mathrm{~m}$ in extent.

\section{Analysis of the Echo Sounder Data}

During all four surveys, pelagic trawls were used to sample the acoustically recorded fish. When converting the $\mathrm{S}_{\mathrm{A}}$-values (nautical area scattering coefficient $\left(\mathrm{m}^{2}(\mathrm{nmi})^{-2}\right)$ ) allocated to the target species, to fish biomass, the mean backscattering cross section was calculated from standard target strength relation (TS), depending on fish length (L $(\mathrm{cm})$ ). For the two surveys along the coast of Africa, TS = $20 \log \mathrm{L}-70.5$ was used as measured for southern African sardine [20] and for the Norwegian spring-spawning herring TS $=20 \operatorname{logL}-71.9$ [21]. The mean weight and length of the main target species in the catch were used in the conversion of echo intensities to fish biomass. The Norwegian springspawning herring had a mean length of $31 \mathrm{~cm}$ and a mean weight of $200 \mathrm{~g}$ in 1997 and of $32 \mathrm{~cm}$ and $210 \mathrm{~g}$ in 1998. In Namibia 1994, the catch was mainly pilchard with a mean length of $24.2 \mathrm{~cm}$ and a weight of $120 \mathrm{~g}$. The target species, sardinella, in Angola 1995 had a mean length of $32.4 \mathrm{~cm}$ and a weight of $250 \mathrm{~g}$.

For all the four surveys the biomass estimates from the sonar were tested for significant differences against the estimates from the echo sounder. The sonar and echo sounder estimates were for each of the surveys also tested for correlation and the depth distribution of the biomass estimates from the echo sounder was plotted.

\section{RESULTS}

\section{School Distribution in the Sonar Recording Range}

The biomass estimations from the sonar were based on the school recordings in the recording range, 50 to $300 \mathrm{~m}$ to the side of the vessel. Ideally the school frequency distribution and the summed school areas in the recording range should represent the undisturbed school distribution, but in all the four surveys the school recording frequency decreased with increasing range (Figs. 4-7). In three of the four surveys the recording frequency decreased fast in the range close to the vessel $(50$ to $80-100 \mathrm{~m})$ followed by a more stable and slightly decreasing trend in the recording frequency from 80 100 to $300 \mathrm{~m}$. In N.S.97 a smoothly decreasing recording frequency was found during the whole recording range. Regression analysis showed that the mean school area increases significantly $(p<0.01$, by factors from 0.4 to 0.9 ) and the $\mathrm{C}_{\text {sum }}$ decreased (significantly; $\mathrm{p}<0.01$, except from Ang. $95 ; \mathrm{p}=0.05$, with factors from -0.2 to -1.8 ) with range for all four surveys (Table 1, Figs. 4-7). In the Norwegian Sea, the reduction of $\mathrm{C}_{\text {sum }}$ with increasing range was higher $(-1.5$ to -1.8$)$ than along the coast of southwest Africa $(-0.2$ to -0.4$)$.

\section{Biomass Estimation}

For three of the four surveys, the biomass estimates obtained by the sonar was significantly higher $(\mathrm{p}<0.01$, Table 2) than those recorded by the echo sounder (Nam.94; 
Table 1. The Regression Expressions between Area and Range ( $r=$ distance school-vessel, 50 to $300 \mathrm{~m}$ ), and $\mathrm{C}_{\mathrm{sum}}$ and Range. $\mathrm{C}_{\mathrm{sum}}$ (Colour Sum) Indicating the Density of the Targets and has No Units due to its Relative Scale. The p-Value and Standard Error (s.e.) for the Association between the Dependent Variable and Range are given

\begin{tabular}{|c|c|c|c|c|c|c|}
\hline & \multicolumn{2}{|c|}{ Regression } & \multicolumn{3}{c|}{ Regression } \\
\hline & Area $\left(\mathbf{m}^{2}\right)$ and Range (m) & p-level & s.e. & C $_{\text {sum }}$ and Range (m) & p-level & s.e. \\
\hline \hline Namibia 94 & Area=-0.1+0.9r & $<0.01$ & 0.02 & $\mathrm{C}_{\text {sum }}=481.0-0.4 \mathrm{r}$ & $<0.01$ & 0.04 \\
\hline Angola 95 & Area $=15.8+0.7 \mathrm{r}$ & $<0.01$ & 0.03 & $\mathrm{C}_{\text {sum }}=403.7-0.2 \mathrm{r}$ & 0.05 & 0.11 \\
\hline Norw. Sea 97 & Area $=31.3+0.4 \mathrm{r}$ & $<0.01$ & 0.02 & $\mathrm{C}_{\text {sum }}=1059.1-1.8 \mathrm{r}$ & $<0.01$ & 0.13 \\
\hline Norw. Sea 98 & Area $=25.6+0.4 \mathrm{r}$ & $<0.01$ & 0.02 & $\mathrm{C}_{\text {sum }}=977.0-1.5 \mathrm{r}$ & $<0.01$ & 0.24 \\
\hline
\end{tabular}

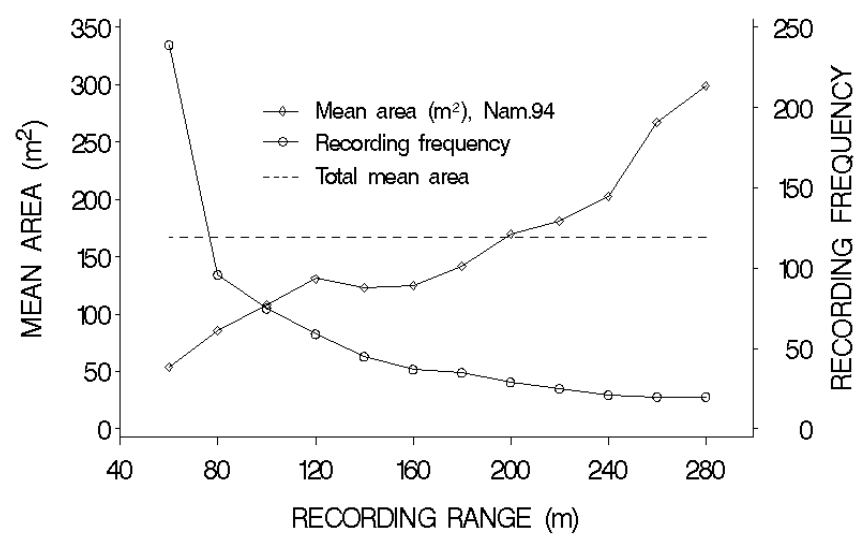

Fig. (4). The recording frequency of schools (circles) at different ranges (distances from the vessel) and the mean school area (diamonds) at corresponding range from the survey off the coast of Namibia in 1994. The mean summed area within the whole detection range is marked (stippled line).

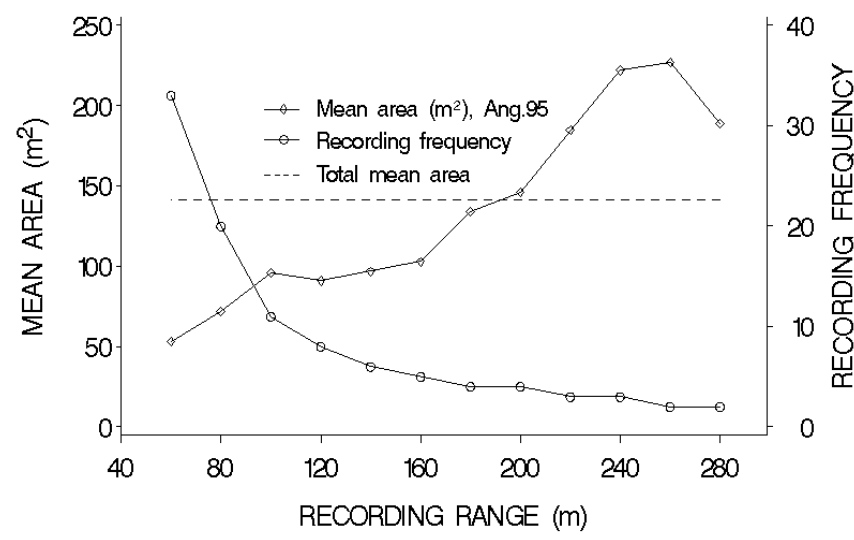

Fig. (5). The recording frequency of schools (circles) at different ranges (distances from the vessel) and the mean school area (diamonds) at corresponding range from the survey off the coast of Angola in 1995. The mean summed area within the whole detection range is marked (stippled line).

Fig. (8), Ang.95; Fig. (9), N.S.97; Fig. (10)), whereas in the last survey (N.S.98; Fig. 11), there was no significant difference ( $>0.01$, Table 2). The estimated biomasses between the four surveys varied with a factor of 1.8 for the echo sounder recordings (the survey with the highest echo sounder estimate divided by the survey with the lowest estimate), compared to a factor of 9.0 for the sonar record-

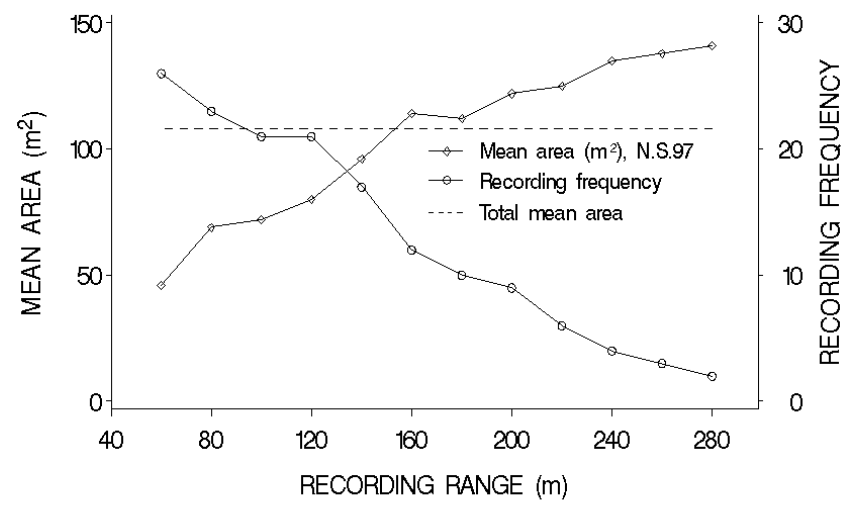

Fig. (6). The recording frequency of schools (circles) at different ranges (distances from the vessel) and the mean school area (diamonds) at corresponding range from the survey in the Norwegian Sea in 1997. The mean summed area within the whole detection range is marked (stippled line).

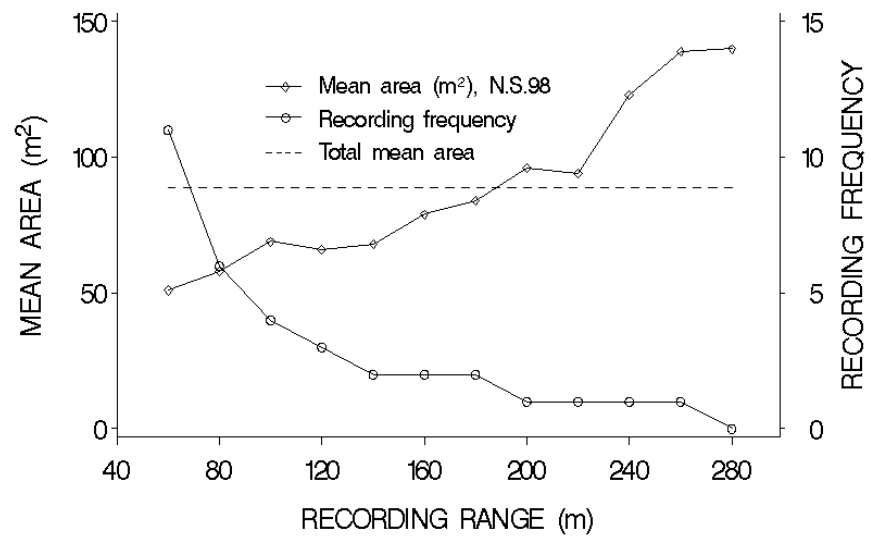

Fig. (7). The recording frequency of schools (circles) at different ranges (distances from the vessel) and the mean school area (diamonds) at corresponding range from the survey in the Norwegian Sea in 1998. The mean summed area within the whole detection range is marked (stippled line).

ings. There was correlation between the biomass estimation from the sonar and echo sounder recordings in N.S.97, N.S.98 and Nam.94 ( $<<0.01$, Table 2). In Ang.95, as the only survey, no correlation between the estimates $(p=0.79$, Table 2) was found.

When comparing the density estimates of the simultaneous sonar and echo sounder recordings for one and one survey, the factor $\left(\rho_{\text {Sonar }} / \rho_{\text {E.I. }}\right)$ varied from 9.4 off the coast 


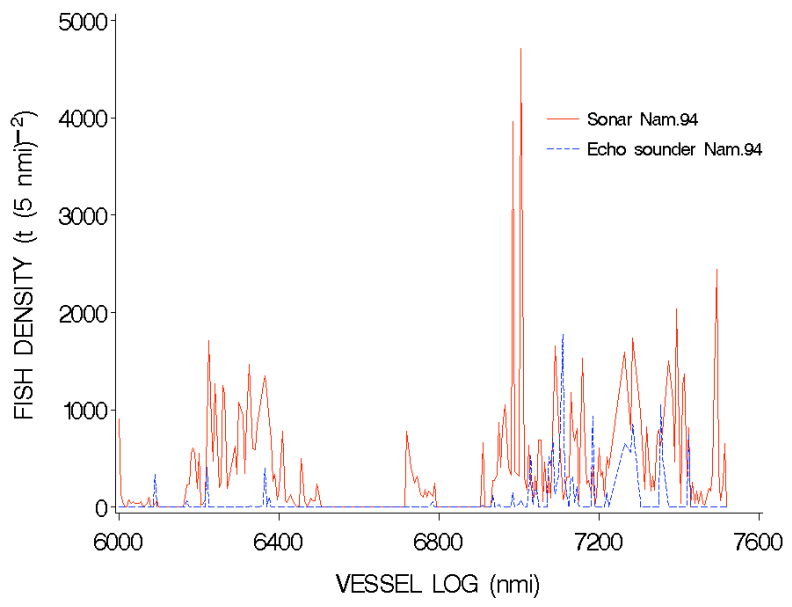

Fig. (8). Fish biomass estimated from the sonar recordings (full line) and echo sounder recordings (stippled line) from the acoustic survey off the coast of Namibia in 1994.

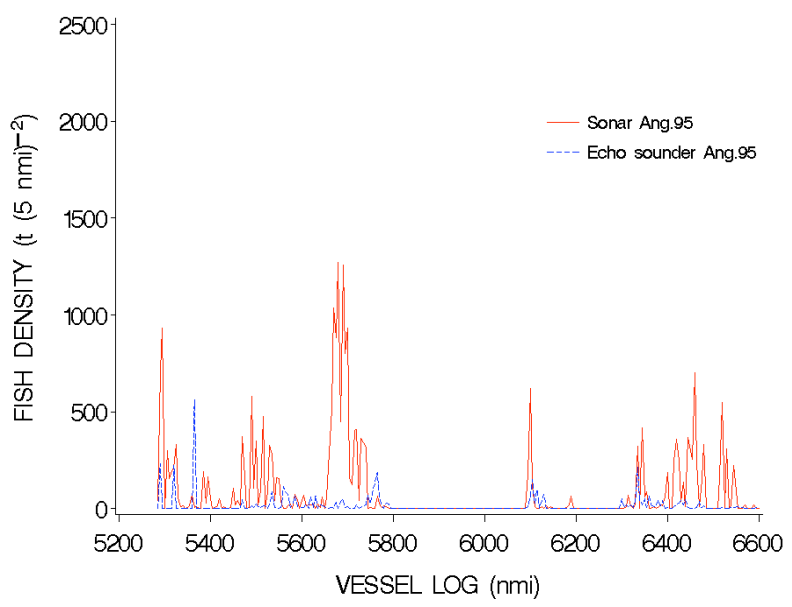

Fig. (9). Fish biomass estimated from the sonar recordings (full line) and echo sounder recordings (stippled line) from the acoustic survey off the coast of Angola in 1995. Vessel log on the horizontal axis refers to the sailed distance of the vessel.

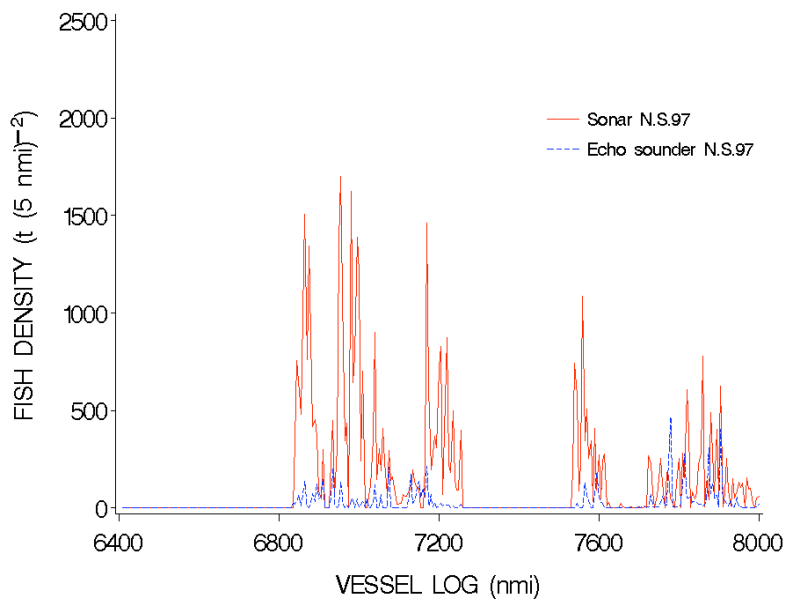

Fig. (10). F Fish biomass estimated from the sonar recordings (full line) and echo sounder recordings (stippled line) from the acoustic survey in the Norwegian Sea in 1997. The nautical miles without observations are representing miles where the observations were manually sorted out due to noise or bad weather conditions. Vessel $\log$ on the horizontal axis refers to the sailed distance of the vessel.

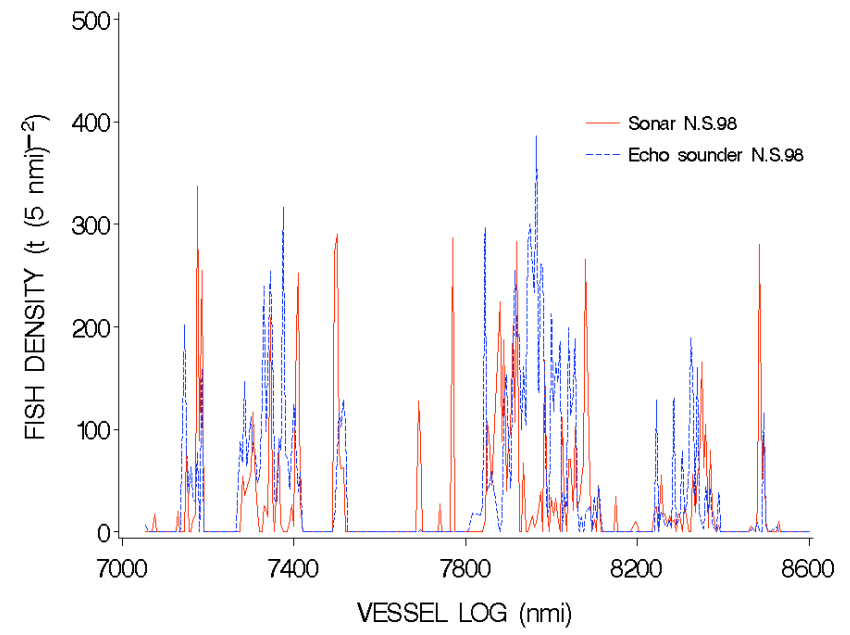

Fig. (11). Fish biomass estimated from the sonar recordings (full line) and echo sounder recordings (stippled line) from the acoustic survey in the Norwegian Sea in 1998. Vessel log on the horizontal axis refers to the sailed distance of the vessel.

of Nam.94 to 4.1 off the coast of Ang.95 (Table 2). For the two years of herring recordings in the Norwegian Sea, the ratio " $\rho_{\text {Sonar }} / \rho_{\text {E.I." }}$ " was 6.1 in N.S.97 compared to 0.7 in N.S.98 (Table 2). In comparable studies the factor " $\rho_{\text {Sonar }}$ ' $\rho_{\text {E.I. }}$ " varied from 0.8 to 3.4 (Table 3 ). Thus the ratios of fish densities obtained by sonar $\left(\rho_{\text {Sonar }}\right)$ to those obtained by echo sounder $\left(\rho_{\text {E.I. }}\right)$ varied both with respect to location and with time within a specific location, which tell us something about the performance of the sonar and echo sounder.

\section{Further Analyses of the Sonar Recordings}

In N.S.97, the mean number of schools recorded per ESDU by the sonar was 7.3 times higher than in N.S.98, $22 \pm 47$ (s.d.) compared to $3 \pm 5$ schools per ESDU. In Nam.94 the mean number of schools per ESDU was $52 \pm 61$ compared to $16 \pm 26$ schools per ESDU in Ang.95. The mean school area for the African surveys was 1.5 times larger than the mean school area in the Norwegian Sea, $130 \pm 258 \mathrm{~m}^{2}$ against $88 \pm 106 \mathrm{~m}^{2}$. The mean school area was 1.2 times higher in N.S.97 than in N.S.98. Using the school area as a converting factor, the greater number and slightly larger schools recorded in N.S.97 resulted in much higher fish density estimate this year. The mean $\mathrm{C}_{\text {sum }}$ was $406 \pm 736$ in the African surveys compared to $793 \pm 756$ in the Norwegian Sea surveys.

The automatic detections by the sonar were compared with manual counting of the schools for 25 nautical miles in N.S.97 and N.S.98 to study the effect of miss sampling of school fragments as a consequence of heavy rolling and pitching of the vessel. Comparing the sonar detections to the manual counting of school resulted in a factor of 1.7 in N.S.98 compared to 3.9 in N.S.97, indicating that the schools were spited up and miss-sampled by the school detection program twice as much in N.S.97 as in N.S.98.

The threshold used to include a received acoustical echo as a potential fish school was set to either 10 or 15 both for N.S.97 and N.S.98 so this could not explain the high variation in estimated biomass from the sonar. For both African studies, the threshold was 10 , so different thresholds was not either an explanation for the variation in sonar 
Table 2. Statistical Comparison by Wilcoxon 2-Sampletest of the Density Estimations from Sonar $\left(\rho_{\text {Sonar }}(t / E S D U) \pm\right.$ s.d.) and the Echo Sounder $\left(\rho_{\text {E.I }}(t / E S D U) \pm\right.$ s.d.), the Densities is Given in Ton $(t) \pm$ Standard Deviation (s.d.) per Elementary Sampling Distance Unit (ESDU). Pearson Correlation Analysis was Used to Test the Correlation between the Density Estimates, " $r$ " is the Pearson Correlation Coefficient and "p" the Significant Level

\begin{tabular}{|c|c|c|c|c|c|c|}
\hline & \multirow{2}{*}{\multicolumn{2}{|c|}{$\begin{array}{c}\text { Correlation analysis } \\
\rho_{\text {Sonar }} v s . \rho_{\text {E.I }}\end{array}$}} & \multicolumn{3}{|c|}{ Mean density estimations } & \multirow{3}{*}{$\begin{array}{c}\text { Proportion= } \\
\rho_{\text {Sonar }} / \rho_{\text {E.I. }}\end{array}$} \\
\hline & & & \multirow{2}{*}{$\frac{\rho_{\text {sonar }} \pm \text { s.d. }}{(t / \text { ESDU) }}$} & \multirow{2}{*}{$\frac{\rho_{\text {E.I }} \pm \text { s.d. }}{(t / \text { ESDU })}$} & \multirow{2}{*}{$\frac{\text { Wilcoxon }}{\text { p-value }}$} & \\
\hline & $\mathbf{r}$ & $\mathbf{p}$ & & & & \\
\hline Namibia 94 & 0.19 & $<0.01$ & $272 \pm 454$ & $29 \pm 135$ & $<0.01$ & 9.4 \\
\hline Angola 95 & 0.02 & 0.79 & $166 \pm 327$ & $40 \pm 239$ & $<0.01$ & 4.1 \\
\hline
\end{tabular}

Table 3. Comparison of Published Fish Density Estimates from Sonar and Echo Sounder Recordings. Density Estimations from Echo Sounder $\left(\rho_{\text {E.I }}\left(t\left(\mathrm{nmi}^{-2}\right)\right)\right)$, and the Ratio $\left(\rho_{\text {Sonar }} / \rho_{\text {E.I. }}\right)$ between the Sonar $\left.\left(\rho_{\text {Sonar }}(t)\left(n m i^{-2}\right)\right)\right)$ and the Echo Sounder. "p/a/rh" Indicating Pilchard/Anchovy/Round Herring. "*” Marks Results from this Study, the Other Results are from Other Studies (18, 16, 5). "Distrib." Indicates Distribution and "Rec.” Indicate Recording

\begin{tabular}{|c|c|c|c|c|c|}
\hline Survey area, year & Species & Time of year & $\rho_{\text {E.I }}\left(t(n m i)^{-2}\right)$ & $\rho_{\text {Sonar }} / \rho_{\text {E.I }}$ & Cause for $\rho_{\text {Sonar }} / \rho_{\text {E.I. }} \neq 1$ \\
\hline Barents Sea 94 & herring & August & 151.7 & 2.1 & near surface distrib./avoidance \\
\hline Norw. Sea 94 & herring & June & 51.8 & 3.4 & near surface distrib./avoidance \\
\hline Norw. Sea 96 & herring & May & 31 & 0.8 & \\
\hline Norw. Sea $98^{*}$ & herring & May & $49 / 5$ & 0.7 & \\
\hline Namibia 94 & $\mathrm{p} / \mathrm{a} / \mathrm{rh}$ & June & 69.2 & 0.9 & \\
\hline Namibia $94 *$ & $\mathrm{p} / \mathrm{a} / \mathrm{rh}$ & Nov./Dec. & $27 / 5$ & 9.4 & near surface distrib. \\
\hline Angola 95* & sardinella & April & $40 / 5$ & 4.1 & \\
\hline
\end{tabular}

biomass estimation off Africa. An attempt to sort out the miss-sampled loose layers in N.S.97 was carried out by comparing the density distribution $\left(\mathrm{C}_{\text {sum }}\right)$ of the two Norwegian Sea surveys. If a group of targets with very low $\mathrm{C}_{\text {sum }}$ could be identified in 1997 this could be a criterion to sort out these loose layers. Unfortunately such a group could not be identified.

\section{School Depth Distribution}

The echo sounder records schools in a narrow sector beneath the vessel and the standard setting of the postprocessing system BEI gives a database output of density in $50 \mathrm{~m}$ vertical sections. The horizontally guided sonar records fish in the upper water column, but yields uncertain depth estimates of the schools, due to the relative wide ping angle in the vertical direction of $10^{\circ}$. For comparison, the total estimated biomass from the sonar was plotted in the 0 to 50 $\mathrm{m}$ interval in the same figures as the echo sounder recordings (Figs. 12-15). The depth distribution of the total estimated fish biomass, based on the echo sounder recordings, was compared. In N.S.98, $87 \%$ of total echo sounder biomass

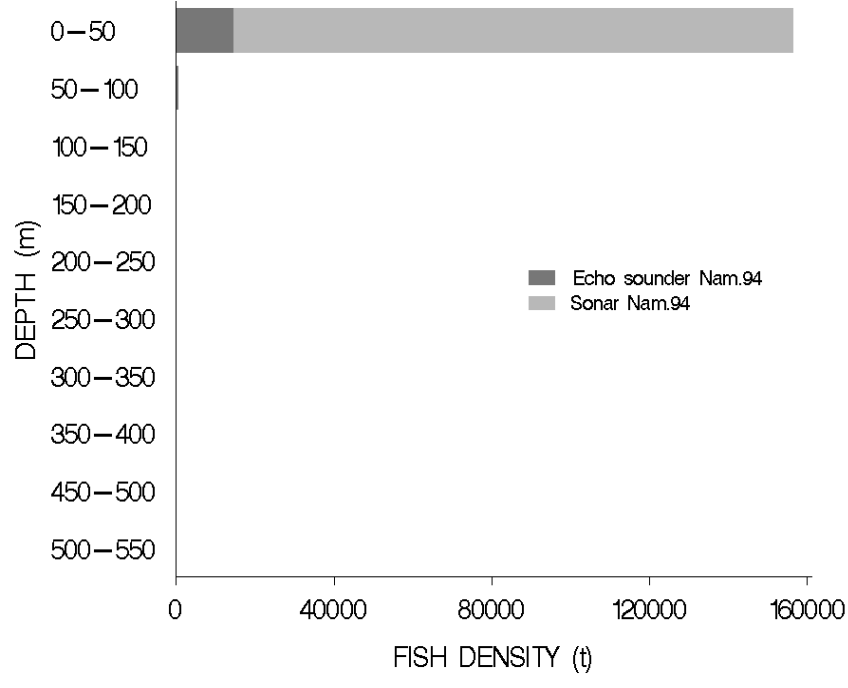

Fig. (12). Depth of the schools recorded by echo sounder (dark grey) and sonar (light grey) from the acoustic survey off the coast of Namibia in 1994. 


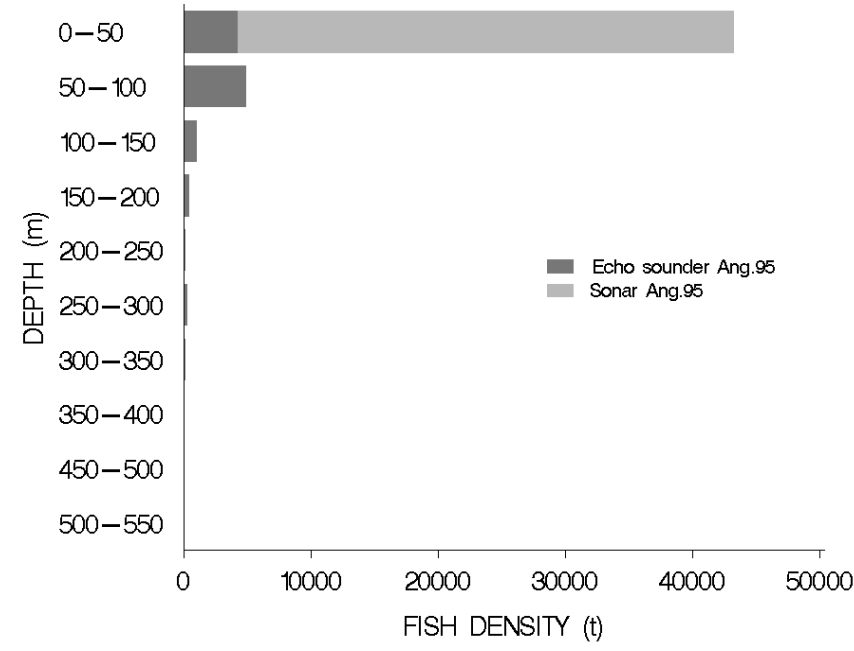

Fig. (13). Depth of the schools recorded by echo sounder (dark grey) and sonar (light grey) from the acoustic survey off the coast of Angola in 1995.

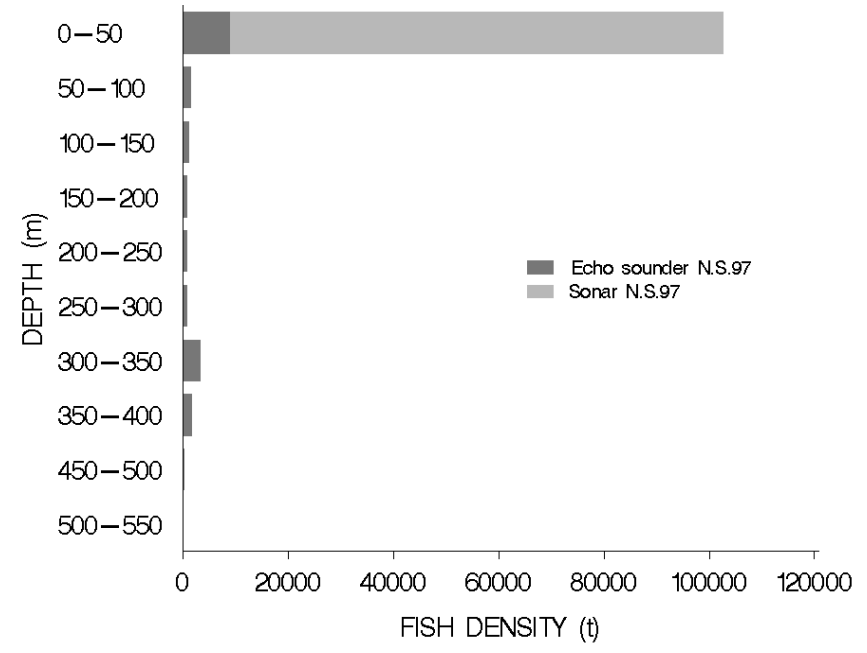

Fig. (14). Depth of the schools recorded by echo sounder (dark grey) and sonar (light grey) from the acoustic survey in the Norwegian Sea in 1997.

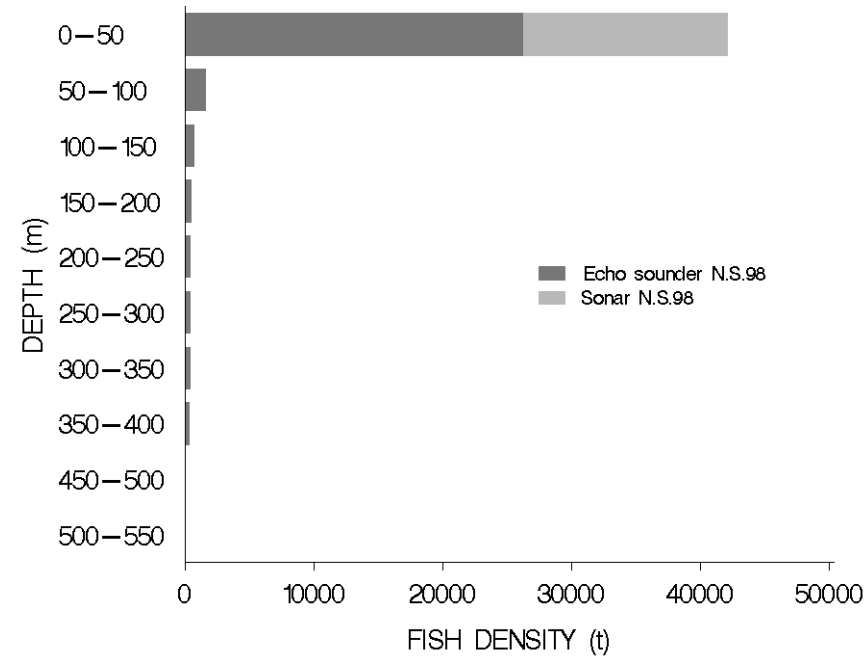

Fig. (15). Depth of the schools recorded by echo sounder (dark grey) and sonar (light grey) from the acoustic survey in the Norwegian Sea in 1998. was recorded in the 0 to $50 \mathrm{~m}$ depth interval, compared to only $49 \%$ in N.S.97. In Nam.94, $97 \%$ of the biomass estimated from echo sounder recordings was observed in the 0 to $50 \mathrm{~m}$ interval while the maximum in Ang.95 was in the 50 to $100 \mathrm{~m}$ interval including $45 \%$ of the biomass.

\section{DISCUSSION}

\section{School Distribution in the Sonar Recording Range}

If all schools were detected and there was no influence on school behaviour from the approaching vessel, one would expect a uniform distribution of schools with range, given equal distribution of schools in the recording depth of the sonar. But schools were not evenly distributed in the sonar recording range, reaching 50 to $300 \mathrm{~m}$ perpendicular to the vessel.

In three of the surveys the highest recording frequency was found in the range closest to the vessel (50 to 80-100 $\mathrm{m})$, where after only a slow decline in the recording frequency was observed out to $300 \mathrm{~m}$. In N.S.97 the recording frequency showed an even reduction in the whole recording range. It is not obvious way a different pattern was found in N.S.97, it could be due to high sound extinction caused by the bad acoustic conditions, but also interruption of data recording due to rolling and pitching of the survey vessel and not well defined schools [22-24]. Because the main behavioural occupation of the fish in the two Norwegian Sea surveys in May month are feeding, differences in sensitivity to vessel noise due to different main behavioural occupation is not likely a cause of the different recording frequency between N.S.97 and N.S.98. In all four surveys the high number of schools in the recording range closest to the vessel was probably due to school avoidance caused by the increased noise and possibly hydrostatic pressure from the approaching vessel [2].

Regression analysis showed an increased mean area and a decreasing in the $\mathrm{C}_{\text {sum }}$ of schools with increasing range for all the four surveys. There are several factors that may cause the mean school area to increase with range. Due to sound extinction there will be a tendency of reduced detection of the smallest schools in the outer range. Because the number of recorded schools per observation volume slightly decreases with increasing range the effect of increased mean school area is strengthened. Avoiding schools are found to increase in school density, probably causing to reduced area for the school closest to the vessel [5]. But the main reason for area increase was probably increased beam with. Hence it is a combination of behavioural, but mainly technical factors that make the mean school area to increase with range. A compensation for increased area with range should be a goal in further evolvement of the automatic post-processing programs.

The echo intensity $\left(\mathrm{C}_{\text {sum }}\right)$ decreased with increasing range in all four surveys (for Ang.95 $\mathrm{p}=0.05$, not strictly significant by a p-level of 0.01), faster in the Norwegian Sea than off the coast of Africa. This can be an effect of higher extinction rate because of higher mean $\mathrm{C}_{\text {sum }}$ in the Norwegian Sea surveys compared to the ones along the southwest coast of Africa. 


\section{Biomass Estimation}

The biomass estimations based on the sonar recordings were significantly higher than those based on traditional echo integration of echo sounder data in three of the four surveys, Nam.94, Ang.95 and N.S.97, while in N.S.98 there was no significant difference. Also in other studies the biomass estimations from simultaneous sonar and echo sounder recordings differed [5, 16, 18].

The biomass estimates from the echo sounder recordings are on the same level for N.S.97 and N.S.98, while the ratio between the echo sounder and sonar estimates are not comparable. This indicate that the sonar recordings are biased by factors that echo sounder recordings not are that sensitive for, and it can be assumed that the high sonar recording in N.S.97 was caused by other factors than a high biomass of herring. Also the biomass estimations from the sonar for Nam.94 and Ang.95 are significantly higher than the echo sounder estimates. The more variable and occasionally much higher densities estimated by the sonar were probably caused both by behavioural (distribution, avoidance) and physical (weather, non target sampling) effects.

\section{Factors Influencing Biomass Estimation}

\section{Depth Distribution}

The vertical distribution of the fish is a key factor determining the applicability of the sonar and echo sounder tools for abundance estimations. The schools had a particularly shallow distribution in Nam.94 that probably was the main reason for the high biomass estimate from the sonar this year. The shallow distribution may also have contributed to the occurrence of the lowest estimated biomass from the echo sounder recordings among these four surveys, caused by reduced availability. Near surface distribution are also shown to be a reason for high sonar estimation in other surveys $[5,16,18]$.

Ang.95 was the only survey that did not show correlation between the density estimates from the sonar and the echo sounder. Ang.95 was the survey with the lowest percentage of total biomass being recorded in the 0 to $50 \mathrm{~m}$ depth interval. The deeper distribution this year probably made the school recordings on the echo sounder less correlated to the school recordings on the sonar.

The depth distributions of schools in the two Norwegian Sea surveys were also clearly different. Both in N.S.97 and N.S.98 schools were recorded down to a depth of about 500 $\mathrm{m}$, but in N.S.98, $92 \%$ of the biomass was observed in the 0 to $100 \mathrm{~m}$ interval compared to $57 \%$ in N.S.97. Thus the schools were more available for the sonar in 1998 than in 1997 and a higher sonar than echo sounder biomass estimate could be expected in 1998. However, the estimates from the sonar showed the opposite trend with a much higher biomass estimate in 1997, the reason for this was probably a combination of the weather condition, non target sampling and fish horizontal distribution.

\section{Weather}

An important factor that influenced the quality of the sonar recordings was the weather condition that resulted in band of noise and splitting of schools, as seen partly in
N.S.97 and in Ang.95. Heavy rolling and pitching of the vessel separated single schools into several fragments that were miss-sampled as separate schools by the detection program, and erroneous increased the biomass estimates. A direct comparison of the two estimates should therefore only be made under good detection periods for both systems. Factors estimated during favourable periods could be extrapolated to other periods when only echo sounding from a protruding keel is available. However, in bad weather, there is a significant increase of the background noise level, and the reaction threshold of fish is usually higher. Vessel avoidance is therefore generally assumed to be less, and the extrapolation suggested may not be valid.

\section{Non-Target Sampling and Fish Distribution}

The mean school area was slightly larger in N.S.97 but the main difference was the about seven times higher mean number of schools per ESDU recorded in N.S.97 than in N.S.98. A problem with the N.S.97 data and a period of the Nam.94 survey were the occurrence of more or less patchy, low density continuous layers, probably plankton or small schools of arrival pelagic fish, fouling the herring measurements. The densest parts of these layers were likely misssampled by the school detection program as schools, and the calculated fish densities could therefore be too high. In N.S.97 a thin undulating layer mainly in the upper 30 to 100 $\mathrm{m}$ could be identified, which was not observed in N.S.98 [25, 26]. The layer was identified as herring and probably contributed to a great difference in biomass estimation between the sonar and the echo sounder. In N.S.97 there was also reported a high amount of 1-group blue whiting (Micromesistius poutassou) [25] and part of this layer could have added to the high sonar estimation in N.S.97. In N.S.98 there were also nautical miles with low-density, more or less patchy fish distributions, but nautical miles with clearly definite schools were more prevalent than for N.S.97.

A solution when continuous mainly low density layers occur, may be to increase the detection threshold and then reduce the amount of unwanted no-target echoes. Presently, however, this can only be done during the in situ recording, but in future hopefully also in a more advanced postprocessing program. The mean $\mathrm{C}_{\text {sum }}$ for the African surveys was a factor of about 0.5 lower than the mean $C_{\text {sum }}$ for the Norwegian Sea surveys. During the surveys the school densities were thus higher for the herring in the Norwegian Sea than for the pilchard, anchovy and round herring schools in Nam.94 and the sardinella schools in Ang.95. This is also why a higher conversion factor from area to biomass is used for Norwegian Sea surveys compared to surveys undertaken on the African southwest coast.

\section{CONCLUSIONS}

This paper discusses comparison of biomass estimates performed with simultaneous echo sounder and sonar recordings done in different locations, under different conditions, and in two successive years in the same location. In N.S.97 the echo sounder and sonar biomass estimations could not be directly compared due to that heavy rolling and pitching of the vessel interrupted sonar school recordings and biomass estimation. In N.S.98 the sea was calmer and the fish was distributed in more defined schools and with the majority of 
the echo sounder registrations in the upper depth interval, which made the biomass estimates comparable. In Ang.95 the echo sounder records most fish in the depth interval $50-$ $100 \mathrm{~m}$. This deeper distribution is more suitable for recording by the echo sounder, so unless the sonar is tilted more than $5^{\circ}$ the estimations would be of fish occurring at different depths. In Nam.94 almost all observations from the echo sounder was in the upper interval 0 to $50 \mathrm{~m}$. This represent a fish depth distribution suitable for the sonar, still effected by loose distribution, while the echo sounder probably missed schools due to the blind zone and avoidance.

The plausibility of the density estimation from the sonar recordings was found to depend on weather conditions, recording of unwanted targets, school structure and the depth distribution. For good sonar recordings the sea should be calm and the fish schools should generally be well defined. Further "valid" abundance estimates ideally require compensation for behaviourally bias and a precise transformation from the acoustic recording to the biomass estimates.

For direct comparison of simultaneous abundance estimates from sonar and echo sounder recordings, the fish must be in the recording range of both equipments and the physical conditions should be such that both equipments could obtain reliable recordings. The target must be deep enough for echo sounder recordings and the sonar tilted to cover the main depth distribution of the fish. A given overlapping depth interval could then be selected for further studying.

\section{ACKNOWLEDGEMENTS}

We are grateful to Dr. Anders Fernø, Dr. Ingvar Huse and Dr. Egil Ona for their constructive comments on the manuscript. The Norwegian Research Council supported the first author to a 3-year scholarship under the program "Fisheries research in developing countries".

\section{REFERENCES}

[1] Aglen A. Sources of errors in acoustic estimation of fish abundance. In: Fernø A, Olsen S, Eds. Marine Fish Behaviour in Capture and Abundance Estimation, Oxford: Fishing News Books 1994; pp. 107-33.

[2] Soria M, Fréon P, Gerlotto F. Analysis of vessel influence on spatial behaviour of fish schools using a multi-beam sonar and consequences for biomass estimates by echo-sounder. ICES J Mar Sci 1996; 53: 453-48.

[3] Olsen K, Angell J, Løvik A. Quantitative estimations of the influence of fish behaviour on acoustically determined fish abundance. FAO fish rep 1983, 300:139-49.

[4] Fréon P, Misund OA. Dynamics of pelagic fish: distribution and behaviour: effects on fisheries and stock assessment. Oxford, Fishing New Books 1999; p. 348.

[5] Misund OA, Coetzee J. Recording fish schools by multi-beam sonar: potential for validating and supplementing echo integration recordings of schooling fish. Fish Res 2000; 47: 149-59.
[6] Lamboeuf M, Burczynski J, Bencherifi S, Chbani M, Elminowicz A. 1983. Acoustic evaluation of the biomass of the stock of sardines in Morocco from 1979 to 1981. Combination of soar and vertical sounder estimations. In: Nakken O, Venema SC, Eds. Symposium on fisheries Acoustic. Selected papers of the ICES/FAO symposium on fisheries acoustics, Bergen, Norway, 2124 June 1982, 1983, FAO fisheries report. Rome (FAO FISH. REP.), no. 300. pp. 197-207.

[7] Aglen A. Sonar observations of the behaviour of herring schools relative to a fishing vessel. Tromsø ICES-FAST Working Group, May 1985; p.7 (mimeo).

[8] Misund OA, Aglen A. Swimming behaviour of fish schools in the North Sea during acoustic surveying and pelagic trawl sampling. ICES J Marine Sci 1992; 49: 325-34.

[9] Love RH. A model for estimation distributions of fish school target strengths. Deep-sea Res 1981; 28A(7): 705-25.

[10] Mitson RB.. Fisheries Sonar. Farnham, Fishing News Books Ltd. England: 1983; p. 287.

[11] Misund OA, Aglen A, Beltestad A, Dalen J.. Relationships between the geometric dimensions and biomass of schools. ICES J Mar Sci 1992 49: 305-15.

[12] Misund OA, Aglen A, Frønæs E. Mapping the shape, size and density of fish schools by echo integration and high-resolution sonar. ICES J Mar Sci 1995; 52:11-20.

[13] Misund OA. Abundance estimation of fish schools based on a relationship between school area and school biomass. Aquat Living Resour 1993; 6: 235-41.

[14] Misund OA, Totland B, Floen S, Aglen A. 1994. Computer-based detection of schools by multi-beam sonar. In: Bjørnø L, Eds. Proceedings of the Second European Conference on Underwater Acoustics. Amsterdam: Elsevier 1994; pp. 815-20.

[15] Dalen J, Nordbø PE, Totland B. SODAPS 950: A workstationbased system on quantification and visualisation of data from fish schools and sonar. In: Zakharia ME, Chevret P, Dubail P, Eds. European Conference on Underwater Acoustics: ECUA 2000, Lyon 10-13 July 2000, France, Office for official publications of the European Communities, Luxemburg. pp 1491-1496.

[16] Misund OA, Vilhjálmsson H, Jákupsstovu SH, et al. Distribution, migration and abundance of Norwegian spring spawning herring in relation to the temperature and zooplankton biomass in the Norwegian Sea as recorded by coordinated surveys in spring and summer 1996. Sarsia 1998; 83: 117-27.

[17] SAS. SAS Institute Inc. SAS/STAT TM User's Guide 1988, Release 6.03.

[18] Misund OA, Aglen A, Hamre J, et al. Improved mapping of schooling fish near the surface: comparison of abundance estimates obtained by sonar and echo integration. ICES J Mar Sci 1996; 53: 383-8.

[19] Foote KG, Knudsen HP, Korneliussen RJ, Nordbø PE, Røand K. Postprocessing system for echo sounder data. J Acoust Soc Am 1991; 90: 37-47.

[20] Barange M, Hampton I, Soule M. Empirical determination of in situ target strengths of three loosely aggregated pelagic fish species. ICES J Mar Sci 1996; 53: 225-32.

[21] Foote KG. Fish target strength for use in echo integration surveys. J Acoust Soc Am 1987; 82: 981-7.

[22] Gunderson DR. Surveys of fisheries resources. New York: John Wiley \& Sons Inc 1993, p. 248.

[23] Misund OA. Underwater acoustic in marine fisheries and fisheries research. Rev Fish Biol Fish 1997; 7: 1-34.

[24] Xianyong Z, Ona E. Estimations and compensation models for the shadowing effect in dense fish aggregations. ICES J Mar Sci 2003; 60: $155-63$.

[25] Anon 1997. ICES Council Meeting 1997, Y:04. p. 34

[26] Anon 1998. ICES Council Meeting 1997, D:03. p. 61. 